\title{
AS DISPARIDADES NOS SISTEMAS DE ENSINO BAIANO E MINEIRO: UMA ANÁLISE EXPLORATÓRIA ATRAVÉS DE INDICADORES EDUCACIONAIS
}

THE DISPARITIES IN THE EDUCATIONAL SYSTEMS OF BAHIA AND MINAS GERAIS: AN EXPLORATORY ANALYSIS THROUGH EDUCATIONAL INDICATORS

\section{CLÁUDIA CRISTINA RIOS CAXIAS DA COSTA* RENATO MOREIRA HADAD**}

\section{R E S U M O}

No Brasil, país de dimensões continentais e de grandes diferenciações internas, é cada vez mais frequente a utilização do desempenho dos alunos em avaliações externas da aprendizagem, com intuito de nortear as políticas educacionais. Indicadores globais de qualidade da educação, a exemplo do Índice de Desenvolvimento da Educação Básica (Ideb), denotam que os sistemas educacionais brasileiros devem ser avaliados sob a ótica dos seus processos de ensino, gestão, aprendizado e trajetória escolar dos alunos. Este estudo buscou evidenciar, através das Taxas de Rendimento e Distorção Idade-Série - no quinquênio 2011-2015 - as desigualdades educacionais entre Bahia e Minas Gerais, unidades federativas contíguas, histórica e culturalmente afins, mas com indicadores educacionais dissemelhantes. A trajetória da pesquisa possibilitou verificar que, apesar da taxa de aprovação dos alunos na educação básica estar impulsionando o fluxo escolar na Bahia e Minas Gerais, a redução da taxa de fecundidade nestas unidades federativas (UFs) vem favorecendo a redução no número de matrículas em todos os níveis (fundamental I, Il e médio), principalmente no ensino médio, pior segmento da educação básica, sobremaneira a baiana.

PALAVRAS-ChAVE: Brasil, Desigualdades educacionais, Indicadores educaionais, Sistemas de Ensino, Taxa de rendimento, Taxa de fecundidade.

\section{A B S T R A C T}

In Brazil, country of continental dimensions and large internal differentiations is increasingly the use of student performance in external evaluations of learning, in order to guide educational policies. Global indicators of quality of education as basic Education Development Index (Ideb) denotes that the Brazilian educational systems must be evaluated from the perspective of educational processes, management, learning and pupil's school career. This study sought to highlight, through rates of income and age-Grade Distortion-in the fiveyear period 2011-2015 educational inequalities between Bahia and Minas Gerais States, historically and culturally related contiguous, but with educational indicators dissimilar. The trajectory of the research made it possible to note that, despite the approval rate of pupils in basic education be boosting school flow in Bahia and Minas Gerais, the reduction in the fertility rate in these States (UFs) has been favouring the reduction in the number of enrollments at all levels (elementary I, II and high school), especially in high school, worst segment of the basic education, mainly in Bahia State.

KEYWORDS: Brazil, educational inequalities, education system, educational indicators, Income rate, fertility rate.

\footnotetext{
"Doutora em Geografia - Tratamento da Informação Espacial pela Pontifícia Universidade Católica de Minas Gerais (PUC-Minas), coordenadora do Centro de Extensão, Pesquisa e Pós-Gradução (CEPPG) e docente na Faculdade Dom Pedro II de Tecnologia. Correo electrónico: riosdacosta@gmail.com

"Docente (Dr) em Ciências da Computação e pesquisador residente do Departamento de Demografia da Universidade Federal de Minas Gerais. Correo electrónico: renatohadad@oi.com.br
} 


\section{INTRODUÇÃO}

A Educação é uma temática sempre apropriada, que nunca se esgota, posto que ser inerente às sociedades humanas e, como tal, sujeita a inovações. Sendo um tema complexo, deve ser tratado com atenção, devido à existência de fatores limitantes porque, por mais que se analise ou, sempre haverá um gargalo, um fator não previsto, que afetará as estatísticas educacionais, no tocante as políticas públicas de intervenção.

As principais características das desigualdades regionais do sistema educacional brasileiro enfatizam diferenças socioeconômicas entre as regiões mais desenvolvidas (Sul e Sudeste) e as menos desenvolvidas do país (Norte e Nordeste). A evolução positiva dos principais indicadores educacionais não se deu de forma homogênea, muito menos seguiu o mesmo ritmo em todas as regiões, fator que se soma ao quadro de diferenças entre as regiões Norte e Nordeste em relação aos do sul brasileiro. Os sistemas de ensino baiano e mineiro são exemplos do aprofundamento do grau de desigualdade regional e interestadual. Indicadores de rendimento escolar e de desempenho dos sistemas de ensino no Sistema Nacional de Avaliação da Educação Básica (SAEB) mostram que, apesar de fronteiriças, estas unidades federativas são díspares educacionalmente. Ao lançar luzes sobre as divergências educacionais entre Bahia e Minas Gerais buscou-se, nesse estudo, e como se tem dito, verificar se, apesar da taxa de aprovação dos alunos na educação básica estar impulsionando o fluxo escolar na Bahia e Minas Gerais, a redução da taxa de fecundidade nestas unidades federativas (UFs) vem favorecendo a redução no número de matrículas em todos os níveis (fundamental I, II e médio), principalmente no ensino médio, pior segmento da educação básica, sobremaneira a baiana.

\section{RELEVÂNCIAS DO ES- TUDO SOBRE AS DE- SIGUALDADES EDUCA- CIONAIS E OBJETIVOS DA PESQUISA}

Sendo o Brasil um país marcado por expressivas disparidades regionais, bem como dotado de grandiosa e complexa estrutura territorial, torna-se cada vez mais frequente a busca por informações espaciais mais abrangentes e detalhadas, sobretudo no que tange ao nível de escolaridade de sua população. O desempenho da educação brasileira, o contexto social no 
qual ela se desenvolve, o mecanismo de redistribuição dos recursos visando à equidade, o acesso ao ensino fundamental e médio, a evolução dos estudantes dentro do sistema vigente e a proficiência por eles alcançada, são pontos que motivam a pesquisa acerca de uma temática tão atual e necessária ao desenvolvimento de uma nação.

A relevância científica dessa pesquisa ${ }^{1}$ está relacionada à disponibilização, àqueles que têm interesse pelo campo da educação, em especial aos Estados da Bahia e Minas Gerais, informações sobre efeitos da dinâmica acerca das taxas de rendimento e distorção idade-série, como indicadores educacionais que evidenciam a sua eficácia. Também pelo fato dos trabalhos acadêmicos relacionados ao desempenho e à distorção idade-série, levando-se em consideração unidades geográficas menores do que as unidades da federação, são parcos, incipientes e repletos de limitações, quanto a detalhamento da situação do educacional no Brasil, em particular, nas unidades federativas baiana e mineira.

As desigualdades regionais observadas no Brasil geram fragilidades socioeconômicas e como tal, são considerados entraves ao seu processo de desenvolvimento. Assim, a redução das

' Estudos iniciados em 2007, por ocasião do desenvolvimento e conclusão, em 2011, da Tese de desigualdades deve ser objeto de políticas públicas eficazes, pois o mercado não se interessa por localidades sem viabilidade econômica, capital social e infraestrutura disponível.

De acordo com Enguita (1996), cada unidade federativa tende a homogeneizar a oferta de vagas no sistema educacional, para além das fronteiras regionais, reduzir as desigualdades, dentro de limites técnica e economicamente factíveis, entre os meios urbano e rural, mesmo porque é seu dever assegurar o acesso à educação de qualidade, para toda a sociedade.

O Instituto Brasileiro de Geografia e Estatística (IBGE, 2010) denota que Minas Gerais é o segundo estado brasileiro mais populoso, o maior estado da região Sudeste, e o quarto do país em área territorial, possuindo a terceira economia, abaixo apenas de São Paulo e Rio de Janeiro. A Bahia é a quarta unidade federativa brasileira mais populosa, destaque econômico na região Nordeste e quinta em extensão territorial.

De acordo com Cunha e outros (2002), diante da contínua e crescente descentralização das ações governamentais e da importância que o nível local vem ganhando no planejamento estratégico e na implementação de políticas públicas, a geração de informações

Doutorado "Os sistemas de ensino baiano e mineiro: Uma análise das desigualdades regionais utilizando indicadores escolares 2007 - 2009". 
educacionais para os municípios passa a ser não apenas uma grande demanda, mas, principalmente, uma necessidade e prioridade.

Se, por um lado, deva-se reconhecer que um bom planejamento e ações eficazes somente podem ser levados a cabo a partir do conhecimento detalhado das realidades locais ou regionais, por outro, não se pode negar a importância dos diagnósticos setoriais genéricos como forma de identificar focos prioritários de ação, sejam estes subgrupos demográficos e/ou sociais, setores de serviços ou mesmo espaços geográficos.

A proximidade geográfica é capaz de estabelecer a criação de vínculos analíticos entre unidades federativas, facilitando a compreensão de um dado cenário. Entende-se, assim, que boa parte dos estudos acerca de políticas públicas está associada a fenômenos contínuos no espaço, como denota a Figura 1.

Bahia e Minas Gerais, unidades federativas contíguas, histórica e culturalmente similares, mas com indicadores educacionais dissemelhantes, frutos de resultados desiguais das políticas educacionais igualitárias, são exemplos de que nem sempre o que próximo está, igual será.

Apesar da universalização do Ensino Fundamental, entendida como conquista recente do sistema educacional brasileiro, ainda persistem substanciais desigualdades no seu interior, sejam entre os estudantes, entre as escolas, entre classes de uma dada escola e entre as regiões em que se localizam as escolas (Barros et al., 2001; Soares et al., 2001; Soares, 2005; Torres et al., 2005). Corroborando com essa assertiva, Alfonsin (2001) denota que:

A atividade econômica e a herança social distribuem os homens desigualmente no espaço, produzindo desigualdades sociais. Ao mesmo tempo, as desigualdades territoriais refletem, produzem e reforçam desigualdades sociais, com forte influência na cidadania e qualidade de vida.

Diferenciais de nível educacional geram desigualdades de renda e, consequentemente, baixa qualidade de vida. Partindo-se desta premissa, este estudo põe em voga, o cenário proporcionado pelas taxas de rendimento e distorção idade-série na Educação Básica, sobremaneira no que tange à redução das disparidades regionais, particularmente entre os Estados da Bahia e Minas Gerais.

Afora essas questões, evidenciar indicadores educacionais diferenciais da Bahia e Minas Gerais, bem como suas nuances regionais, e estabelecer um diagnóstico preliminar da educação de Minas Gerais e Bahia, denotando o 
Figura 1. Localização limítrofe de Bahia e Minas Gerais

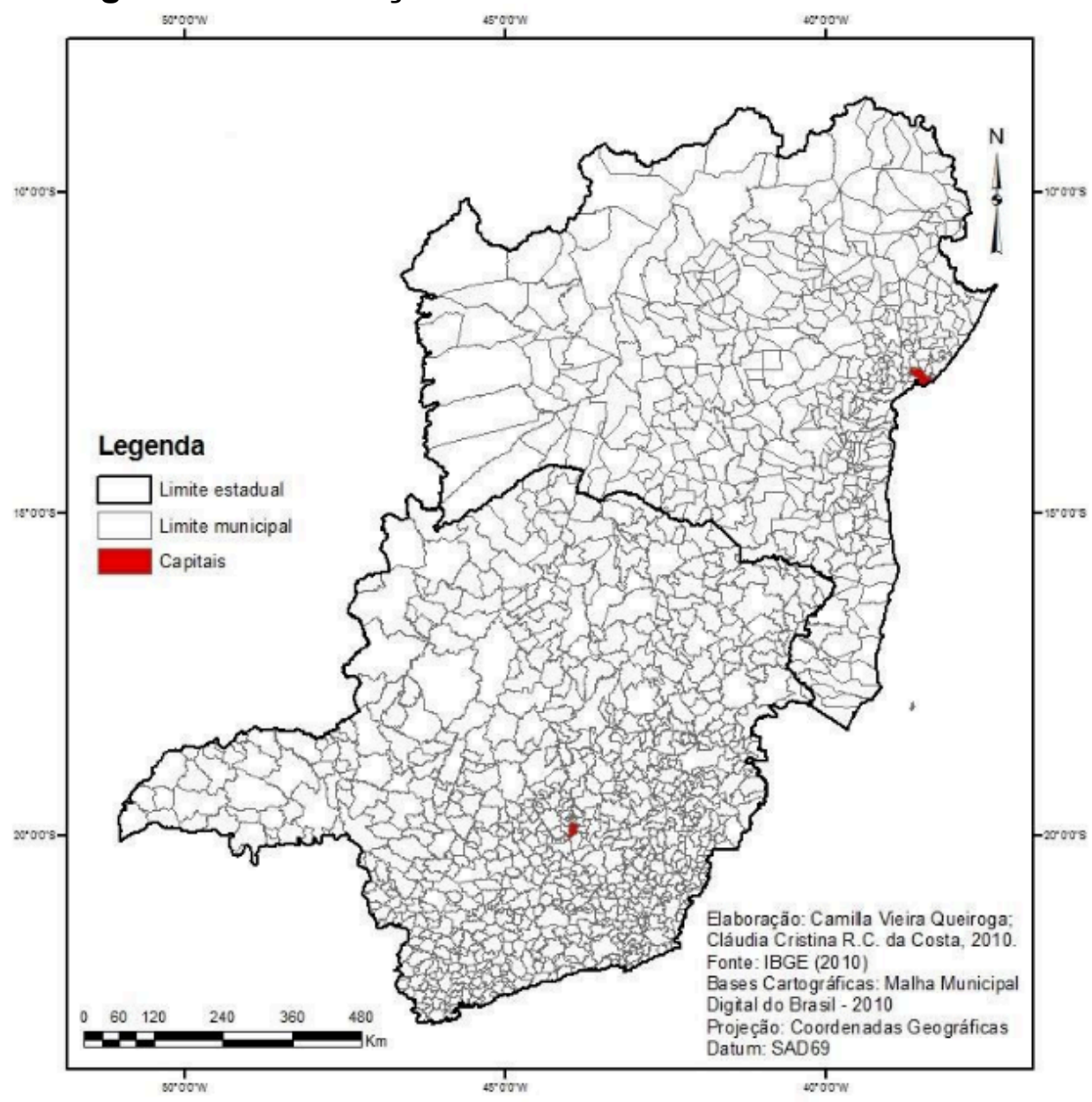

Fonte: Elaboração dos autores

panorama recente - no que tange as taxas de rendimento e distorção idade-série, focalizando essa última constituem como objetivos dessa pesquisa.

\section{ORIGEM DA DESIGUAL- DADE EDUCACIONAL BRASILEIRA: UMA BREVE SÍNTESE}

De acordo com Oliveira (2003), a profunda dissemelhança regional, gerada desde os primórdios da organização do Estado Nacional, é entendida como uma das principais características da educação brasileira. Não é objetivo deste estudo pormenorizar as complexas condições políticas e econômicas que deram origem ao comprometimento desigual das diferentes esferas do Poder Público, principalmente no tocante ao atendimento das necessidades educacionais da população brasileira. No entanto, a abordagem histórica constitui-se, aqui, como contexto a ser mencionado, necessário à compreensão da dificuldade de esta- 
belecimento de uma política de educação que seja norteada pela busca da garantia da cidadania nacional.

Rousseau (1989) distinguiu dois tipos de desigualdade: a desigualdade "natural ou física" - estabelecida pela natureza, consistindo na diferença das idades, da saúde, das forças do corpo e das desigualdades do espírito e da alma - e a desigualdade "moral ou política”, que dependeria de uma espécie de convenção que é estabelecida, ou pelo menos autorizada, pelo consentimento dos homens. A desigualdade "moral" representaria os privilégios de uns em detrimento de outros, a obediência de uns para com os outros, não essencialmente ligada com a desigualdade natural. As desigualdades sociais apresentam princípios próprios dos contextos históricos, políticos e econômicos, centrados nas relações entre as condições de conhecimento e poder, onde noções como a exclusão, inclusão, desenvolvimento desigual, segregação social, dentre outros são utilizados constantemente para explicá-las.

\section{1. Acesso à educação em países do continente americano: algu- mas reflexões}

A questão educacional está relacionada a temáticas debatidas vigorosamente na história econômica, principalmente a institucional. Além das desigualdades e da importância do sufrágio, Engerman e Sokoloff (1997), chamam a atenção para a dotação de fatores, assim designadas às condições iniciais em determinadas regiões, que acabam por marcar por séculos a trajetória das desigualdades:

A análise dos autores é focada na determinação dos agentes de cunho geográfico, bem como na limitação da evolução das instituições. Diante do exposto, não seria incoerente aceitar o argumento de que eles sugerem certo grau de determinismo geográfico, já que as condições iniciais seriam condicionantes para processos futuros. Ao contrário, os autores denotam, apenas, que o fator geográfico também deve ser levado em consideração junto com todos os fatores que levaram a uma colonização de determinado padrão. Fazendo-se uma breve revisão da literatura acerca dos níveis de escolaridade e alfabetização, fica evidenciada a desvantagem dos países latino-americanos, em relação a seus vizinhos do norte e outros países desenvolvidos, principalmente os europeus.

Mariscal e Sokoloff (2000) apresentam algumas hipóteses acerca das origens histórico-institucionais das desigualdades educacionais. Ao contrário dos Estados Unidos, que na primeira metade do século XIX - alicerçados pelo 
common school movement ${ }^{2}$ e por meio da expansão maciça da oferta de escolas públicas - teve seus níveis de alfabetização majorados, os países latino-americanos, embora tivessem condições econômicas para arcar com investimentos dessa significância, não promoveram uma expansão similar da educação básica, devido a questões de ação coletiva, provenientes dos grandes desníveis de renda, capital humano e poder político (idem, p. 163).

A desigualdade educacional nas Américas foi extremamente significativa no século XIX. Em 1870, cerca de 80\% das pessoas com idade acima de dez anos nos Estados Unidos e no Canadá eram alfabetizadas, o correspondente ao triplo dos países progressistas na América Latina e quatro vezes mais que Brasil e México, em relação ao contingente populacional de mesma faixa etária.

Os autores frisam a importância do common school movement nos Estados Unidos e sua ocorrência, logo após grande extensão do direito de voto. Em diversos países, o sufrágio era permitido apenas para alfabetizados. Todavia, a história parece mostrar que países com altas taxas de analfabetismo são mais propensos a manter os analfabetos excluídos do processo

2 Movimento surgido nos Estados Unidos durante a primeira metade do século XIX, na luta pela escola pública, baseada na ideia de "escola eleitoral, enquanto que países cujas restrições foram suspensas, em geral, expandiram a demanda de escolas públicas e, consequentemente, aumentaram os seus níveis de alfabetização (idem, p. 204). Ainda em respeito ao sufrágio, tanto Engerman e Sokoloff (2005), como Mariscal e Sokoloff (2000) enfatizam o atraso dos países latino-americanos mais progressistas tais como Argentina, Chile, Costa Rica e México, que somente obtiveram contingente populacional com direito ao voto, com defasagem de 75 anos em relação aos Estados Unidos.

Essa breve revisão bibliográfica atesta que o panorama educacional nos países da América, sobretudo os latinos, é marcado pela assimetria entre classes sociais.

\section{2. Desigualdades educacionais no Brasil}

Kang (2010) busca suprir a lacuna da historiografia econômica a respeito dos determinantes da defasagem educacional brasileira e suas possíveis relações com o crescimento de longo prazo. Enquanto países como Estados Unidos universalizaram a educação básica pública já no século XIX, o Brasil, defasado em relação a diversos países latino-americanos, somente

comum" elaborada pelo educador abolicionista Horace Mann (1796-1859). 
atingiu níveis mais expressivos de universalização no final do século XX.

O autor questiona, apesar da dificuldade histórica em se obter respostas precisas, se o aumento da oferta educacional teria sido resultado de políticas patrocinadas por elites esclarecidas ou teria sido resultante do aumento do poder político dos grupos sociais subalternos. Desde meados do século XIX foram constatadas críticas intensas e crescentes por parte de alguns representantes da elite ao pouco alcance do ensino primário e, por conseguinte a alta incidência de analfabetismo no Brasil. Muitos já percebiam que o país estava atrasado em relação às principais tendências verificadas nos países considerados desenvolvidos.

O documento "Estatística da Instrucção" (BRASIL，DGE，1916) evidenciou a desvantagem brasileira, no que tange à escolaridade, mostrando que para 1907, a taxa de matrícula no ensino primário, consideradas as crianças com idade entre 7 e 15 anos, não passava de $13,7 \%$. O documento enfatiza também o baixo índice de alfabetização em 1900, que não passava de $25,4 \%$.

Lindert (2004 apud KANG, 2010) demonstra que, para o período de 1870 a 1930, o Brasil apresentou taxas de matrícula mais baixas que os latino-americanos Argentina, Chile, Costa Rica e
México. Em 1930, a taxa costa-riquenha $(40,5 \%)$ era quase duas vezes maior que a brasileira (21,5\%), enquanto a argentina chegava a ser quase o triplo (61,3\%). Para o mesmo período, nos Estados Unidos e Canadá, a quase universalização do ensino básico se concretizava, aferidas taxas de matrículas acima de 90\%, para crianças em idade escolar.

Com referência aos fatores que motivaram as baixas taxas vislumbradas, o documento governamental enfatiza, ainda, como possíveis causas, a exacerbada preocupação com a educação superior - e até certo ponto a secundária - em detrimento da educação primária e qualificação docente do pessoal incumbido de ministrá-la.

Assim, apesar da elite estar ciente da existência do atraso educacional primário, não houve grandes melhoras ao longo da Primeira República. É importante frisar que a expansão da educação no período não teve significativa participação federal, sendo resultado de investimentos estaduais, como previsto pela Constituição, sem gerar grandes melhorias educacionais.

Em 1930, uma das principais medidas do Governo Provisório de Vargas, foi a criação do Ministério da Educação e da Saúde Pública, aumentando a interferência do Governo Federal na educação. Foram empreendidas reformas no ensino, com a introdução de 
disciplinas de caráter técnico-científico no secundário, ao mesmo tempo em que era observado o crescimento razoável das matrículas nesse segmento: 5\% ao ano entre 1933 e 1937.

No entanto, esta situação, no tocante às matrículas, não permaneceu por extenso período. Embora a política do Estado Novo, entre 1934 e 1945, atribuísse certa importância ao ensino primário, entendia também que o Governo Federal não poderia supervisionar esse nível de ensino, devendo sua responsabilidade continuar a ser dos governos estaduais. Além disso, o Ministério da Educação e Saúde Pública acreditava que a formação de uma elite, necessária ao desenvolvimento da nação e capaz de liderar o país era, na época, mais importante. Desta forma, as atenções se voltavam para o ensino secundário, de cunho humanístico voltado às elites, e para o ensino industrial, ante o tardio, mas acelerado processo de industrialização.

Findo o Estado Novo e retomada a democracia, houve um aumento substancial das taxas de matrícula no ensino primário, secundário e industrial. Entretanto, Kang (2010) afirma que a partir do início dos anos 1950 foi verificada nova desaceleração. Embora o período de abertura democrática tenha trazido benesses, ela foi restrita, impedindo que o país superasse seu atraso educacional, uma vez que as políticas continuaram elitistas.

A assertiva de Hirschman (1980) se adéqua ao caso brasileiro. Uma vez que a elite e a classe média possuíam recursos para pagar escolas particulares a seus filhos, tais segmentos sociais não se viam na obrigatoriedade de pleitear melhorias e/ou manutenção da qualidade existente das escolas públicas, que foram sendo abandonadas pelas elites à medida que a rede de escolas privadas se expandiu. Desta forma, e mais intensamente, as escolas públicas destinadas ao ensino fundamental, até então restritas às classes mais abastadas, passaram a ser frequentadas pelas classes sociais de menor poder aquisitivo. Este episódio pulverizou as ações coletivas em favor da maior cobertura e qualidade do ensino público.

Sobremaneira, na década de 1950, a atuação do governo na educação primária foi limitada. O segundo governo Vargas, sob o regime democrático, pouco fez pela educação, priorizando a criação, em 1951, de órgãos administrativos, tais como o Conselho Nacional de Desenvolvimento Científico e Tecnológico (CNPq) e a Coordenação de Aperfeiçoamento de Pessoal de Nível Superior (CAPES). O governo de Juscelino Kubitschek lançou o Plano de Metas, que propunha objetivos 
para cinco setores estratégicos: energia, transporte, indústrias de base, educação e alimentação.

No período 1950 a 1960 o país conheceu as maiores taxas de expansão da alfabetização, resultado da implantação das classes de ensino supletivo na maioria dos municípios. Ainda que a dimensão educacional estivesse em pauta no programa, apenas $3,4 \%$ das verbas foram inicialmente previstas para a educação. O governo Goulart planejou aumento de verbas para a educação, mas, deposto em 1964, não chegou a concretizar os seus intuitos.

Até aqui, verifica-se que em várias ocasiões, a falta de ações e investimentos do Governo Federal contribuiu para a persistência da desigualdade no acesso à educação elementar. Somente a partir dos anos 2000 é que a participação do governo federal no financiamento da educação básica foi melhorada. Constata-se também, que mesmo em períodos mais democráticos onde imperou a democracia, o Brasil, em relação aos demais países, continuou atrasado em termos de matrículas.

No tocante ao grau de centralização, ou de descentralização das estruturas administrativa e financeira, os autores desse estudo, corroborando Kang (2010), se indaga: até que ponto, a população tinha, e ainda tem, influência sobre as ações de governos locais, face aos assuntos educacionais?

\section{3. Desigualdades e os diferen- ciais de acesso}

A atividade econômica, bem como a herança social, distribui os homens desigualmente no espaço, produzindo desigualdades sociais. Ao mesmo tempo, desigualdades territoriais refletem, produzem e reforçam desigualdades sociais, com forte influência na cidadania e qualidade de vida. Segundo Barros e outros (2002), a educação tem impacto direto sobre o crescimento populacional, o ambiente familiar e participação política. Logo, o investimento em educação pode acarretar maior eficiência econômica, redução da pobreza e facilitar a mobilidade social.

Steiner (2006) afirma que há consenso em reconhecer que as desigualdades sociais se originam das disparidades educacionais, principalmente as de natureza escolar, de sua população. Ressalta $o$ autor que uma das alternativas mais eficazes para a redução destas desigualdades se encontra na educação universal de qualidade, pois se estima que cerca de $50 \%$ das desigualdades sociais existentes na sociedade brasileira sejam oriundas da falta de condições propiciadas pela educação. Projeções da crescente escolaridade 
brasileira permitem prever que a desigualdade decresça, mais acentuadamente, a partir de 2017.

Barros e Lam (1993, p. 1) destacam quatro traços indesejáveis da educação no Brasil: a) o nível educacional médio da população é baixo; b) a educação está desigualmente distribuída; c) existe uma correlação alta entre as realizações educacionais das crianças e as de seus pais e avós, indicando a ausência de igualdade de oportunidades; e d) há grandes disparidades regionais nas realizações educacionais das crianças.

Hasenbalg e Silva (2000) destacam que, apesar do déficit histórico na dimensão educacional, as melhorias educacionais alcançadas nas últimas décadas são inegáveis. As análises dessa evolução educacional tendem a destacar o papel do Estado, via alocação de gasto social na esfera educacional e políticas educacionais específicas, que explicam as melhorias obtidas. Existe, neste caso, uma ênfase unilateral na oferta educacional, apontando-se para os esforços do poder público em direção a melhorias no sistema educacional do país. Em alguns estudos econômicos, relacionados à evolução educacional das últimas décadas, foi reservada especial atenção à demanda educacional por parte das unidades familiares. Neste caso, variáveis como renda familiar e o custo oportunidade das famílias para manter os filhos na escola são de suma importância, destacando-se as dificuldades enfrentadas pelos núcleos familiares com rendas mais baixas.

Apesar de importante contexto, os efeitos da rápida urbanização e transição demográfica do Brasil nas últimas décadas, no que tange à composição social das famílias e da clientela escolar, diante das nuances explicitadas anteriormente, são pouco abordados na literatura específica.

A transição demográfica, implicando na redução dos diferenciais de comportamento reprodutivo, resultou em mudanças igualmente rápidas na composição, nos recursos e na estrutura das famílias que redundam em condições sociais mais favoráveis para a população em idade escolar (Hasenbalg e Silva, 2000, p. 3). Faz-se aqui necessário salientar algumas das mudanças mais importantes na estrutura das famílias brasileiras nas décadas mais recentes.

Uma dessas mudanças é que, como consequência da queda da fecundidade ${ }^{3}$, vem ocorrendo uma redução significativa no tamanho médio das famílias e no número de filhos (Vide Quadro 
1), constituindo uma situação mais favorável à educação das crianças.

Quadro 1. Evolução da Taxa de Fecundidade na Bahia e Minas Gerais, 2011-2015

\begin{tabular}{|l|r|r|r|r|r|}
\cline { 2 - 6 } \multicolumn{1}{c|}{} & 2011 & 2012 & 2013 & 2014 & 2015 \\
\hline Bahia & 1,86 & 1,82 & 1,79 & 1,76 & 1,74 \\
\hline Minas Gerais & 1,69 & 1,66 & 1,63 & 1,61 & 1,59 \\
\hline \multicolumn{5}{c}{ Fonte: IBGE/PNAD. }
\end{tabular}

Em contrapartida, devido ao aumento nas taxas de participação econômica feminina, elevou-se a proporção de mães que trabalham, com possíveis efeitos negativos na escolarização dos filhos (Hasenbalg e Silva, 2000, p. 5). Com a ausência das mães, que trabalham fora, muitas crianças, sobremaneira as meninas, correm o risco de não frequentar a escola ou de abandonar os estudos, tanto para cuidar das tarefas domésticas como dos irmãos mais novos. Desta forma, os direitos universais da criança, no que tange ao brincar, receber educação e ser cuidada por seus pais podem ser postos em risco, implicando negativamente no seu bem-estar e futuro status econômico ${ }^{4}$. Essas tendências são claramente evidentes em muitos países em desenvolvimento, como no Brasil, por exemplo.

\section{METODOLOGÍA}

A presente pesquisa, de cunho exploratório, analítico e espacial, permitiu abordar nuances da educação baiana e mineira, pautada no referencial teórico que consta das seções anteriores. A opção por um estudo de natureza quantitativa dos dados disponíveis decorre da possibilidade de emprego dos recursos, técnicas e métodos estatísticos e de geoprocessamento, tão necessários ao desenvolvimento de pesquisas de cunho educacional.

A escolha do período 2011-2015, permitindo a observação da evolução dos índices educacionais nas duas unidades federativas, se deve às mudanças verificadas no Censo Escolar, sobremaneira as relacionadas à data de referência, que passou de março para maio, quando o sistema já está consolidado. Ressalta-se que os dados provêm de estatísticas oficiais (INEP e IBGE), disponíveis publicamente, oriundas, em sua maioria, de registros administrativos obrigatórios.

Não se pretende, neste estudo, esgotar análises conceituais nem metodológicas acerca de temática em voga. $\mathrm{O}$ objetivo maior desta pesquisa é evidenciar, principalmente através dos dados provenientes do INEP, as desigualdades educacionais existentes

são mais propensas a se tornarem cidadãos produtivos e saudáveis no futuro (Berlinsky \& Schady, 2016). 
na Bahia e em Minas Gerais, mesmo porque "o tratamento de dados por meio de indicadores, oferece indícios sobre as questões tratadas, não verdades (...) que fazem aflorar semelhanças, proximidades ou aprovações" (Gatti, 2004, p. 14).

Obtidos os dados, eles foram tratados no programa estatístico SPSS 18, fomentando a confecção de mapas coropléticos, por meio do programa QGIS (versão 2.18), que serviram de objeto para a análise das disparidades regionais propostas. No presente estudo, optou-se por utilizar as variáveis explicitadas no Quadro 2:

Quadro 2. Variáveis utilizadas no trato dos indicadores educacionais, para Bahia e Minas Gerais, 2011 - 2015

\begin{tabular}{|c|c|}
\hline Nome da Variável & Descrição \\
\hline FK_COD_ESTADO & Código da UF \\
\hline FK_COD_MUNICIPIO & $\begin{array}{l}\text { Código do Muni- } \\
\text { cípio }\end{array}$ \\
\hline $\begin{array}{l}\text { ID_DEPENDEN- } \\
\text { CIA_ADM_ESC }\end{array}$ & $\begin{array}{l}\text { Dependência Ad- } \\
\text { ministrativa da } \\
\text { Escola }\end{array}$ \\
\hline $\begin{array}{l}\text { COD_MUNICIPIO_ES- } \\
\text { COLA }\end{array}$ & $\begin{array}{l}\text { Código de muni- } \\
\text { cípio da escola }\end{array}$ \\
\hline $\begin{array}{c}\text { FK_COD_MOD_EN- } \\
\text { SINO }\end{array}$ & Modalidade* \\
\hline FK_COD_ETAPA_EN- & Etapa** \\
\hline PK_COD_MATRICULA & $\begin{array}{l}\text { Código da matrí- } \\
\text { cula }\end{array}$ \\
\hline FK_COD_ALUNO & $\begin{array}{l}\text { Código do aluno } \\
\text { (ID_INEP) }\end{array}$ \\
\hline
\end{tabular}

Fonte: MEC/INEP, 2011-2015 (Microdados do Censo Escolar).

* Ensino regular de 9 anos

** Ensino Fundamental ou Médio
As variáveis geraram os seguintes indicadores, por unidade federativa:

- Número de Alunos do Ensino Fundamental (EF) I e II, para Bahia e Minas Gerais (20112015);

- Número de Alunos do Ensino Médio (EM), para Bahia e Minas Gerais (2011-2015).

Em relação às taxas de rendimento escolar, por unidade federativa:

- Taxas de Aprovação, Reprovação e Abandono no Ensino Fundamental (EF) I e II para Bahia e Minas Gerais (2011-2015);

- Taxas de Aprovação, Reprovação e Abandono no Ensino Médio (EM) para Bahia e Minas Gerais (2011-2015).

O Plano Nacional de Educação (2001) ampliou para nove anos a duração do Ensino Fundamental obrigatório, com início aos seis anos de idade, à medida que for sendo universalizado o atendimento na faixa de sete a $14 \operatorname{anos}^{5}$. Minas Gerais, com percentual máximo de cobertura para o EF de nove anos (Lei $\mathrm{n}^{0}$ 10.172/2001), desde 2005 recepciona alunos com seis anos de idade no $1^{\mathrm{O}}$ ano do EF. A faixa etária correta para o Ensino Médio é de 15 a 17 anos. A Lei $n^{0}$ 10.330/2006, que aprovou o Plano Estadual de Educação da Bahia, estabeleceu o prazo

\footnotetext{
${ }^{5}$ Lei $n^{\circ} 11.274 / 2006$, segundo a qual o ano limite para implementação e obrigatoriedade do Ensino Fundamental de nove anos foi 2010.
} 
até 2012 para implantação do EF de 9 anos).

\section{1. Itinerário Metodoló- gico para o cálculo das taxas de rendimento es- colar e distorção idade- série}

As informações relativas à matrícula inicial e à situação do aluno foram extraídas da base de dados do Educacenso/INEP. Os dados sobre movimento e rendimento escolar, especificamente, são encontradas nas tabelas de movimento e rendimento e de admissão posterior, que constam das Sinopses Estatísticas para o período de estudo. Nesses documentos, o Índice de Desenvolvimento da Educação Básica (Ideb) tem papel fundamental, como importante condutor de política pública em prol da qualidade da educação brasileira.

Criado em 2007, pelo INEP, o Ideb foi concebido para medir a qualidade do aprendizado nacional e estabelecer metas para a melhoria do ensino, funcionando como um indicador nacional de monitoramento da qualidade da Educação pela sociedade, por meio de dados concretos, com o qual essa pode se mobilizar em busca de melhorias. Para tanto, o Ideb é calculado a partir de dois componentes: a taxa de rendimento escolar (aprovação) e as mé- dias de desempenho nos exames aplicados pelo Inep. Os índices de aprovação são obtidos a partir do Censo Escolar, realizado anualmente.

$O$ índice varia de zero a 10 e a combinação entre fluxo e aprendizagem tem o mérito de equilibrar as duas dimensões: se um sistema de ensino retiver seus alunos para obter resultados de melhor qualidade no Saeb ou Prova Brasil, o fator fluxo será alterado, indicando a necessidade de melhoria do sistema. Se, ao contrário, o sistema apressar a aprovação do aluno sem qualidade, o resultado das avaliações indicará igualmente a necessidade de melhoria do sistema. (INEP, 201O)

A Figura 2 evidencia quais são as taxas de rendimento escolar. Para cada instituição de ensino, a partir da soma da quantidade de alunos aprovados, reprovados e que abandonaram a escola ao final de um ano letivo, são geradas as taxas que, por sua vez, concebem o indicador de rendimento, utilizado no cálculo do Ideb. 

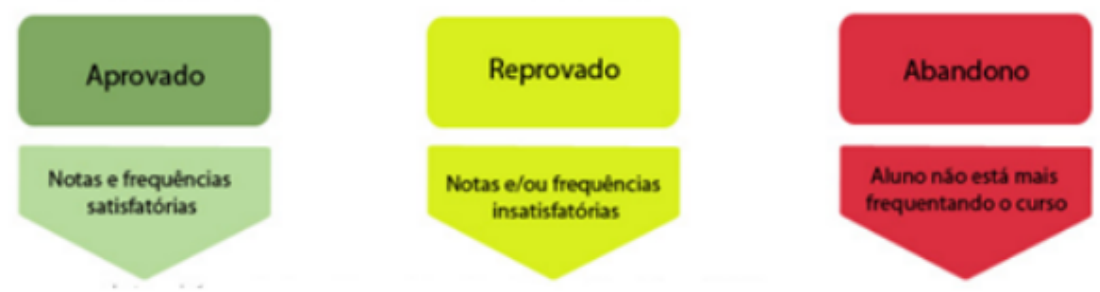

Fonte: Revista Nova Escola, 2012 (adaptado).

Para esse estudo, no cálculo das taxas de rendimento escolar (aprovação e reprovação) e de abandono (quando o aluno deixou de frequentar), foram consideradas as seguintes unidades de agregação: municípios baianos e mineiros e as redes federais, estaduais, municipais e privadas de ensino urbanas e rurais, considerando o conjunto de matrículas que as compõem. As taxas de rendimento escolar foram calculadas ${ }^{6}$ como se segue:

Taxa de Aprovação $=\left[\frac{A P R}{(A P R+R E P+A B A)}\right] * 100$

Taxa de Reprovação $=\left[\frac{R E P}{(A P R+R E P+A B A)}\right] * 100$ Taxa de Abandono $=\left[\frac{A B A}{(A P R+R E P+A B A)}\right] * 100$

Onde,

Taxa de Aprovação + Taxa de Reprovação + Taxa de Abandono $=100$
Segundo Azevedo e Aguiar (2001), a taxa de distorção idade-série, um dos entraves para uma educação de qualidade, permite relacionar o percentual de alunos, em cada série, que se encontra com idade superior à recomendada. Para o cálculo dessa taxa, divide-se o total de matrículas de alunos, acima da idade em determinada série, pelo total de matrículas iniciais nesta mesma série:

$$
T D I S_{j s}=\left(\frac{M A T_{j s_{-} \text {sup }}}{M A T_{j s}}\right) * 100
$$

Onde,

$M A T_{j s_{-} \text {sup }}$ : número de alunos matriculados em uma série $\boldsymbol{s}$, do nivel de ensino $\boldsymbol{j}$, somente para indivíduos com idade superior à adequada.
$M A T_{j s}$ : número de alunos matriculados em uma série $\boldsymbol{s}$ do ensino $\boldsymbol{j}$.

quantidade de matrículas de alunos falecidos; e daqueles que não tiveram a situação de rendimento ou abandono escolar informada. 
Uma das soluções encontradas para redução da distorção idade-série é a adoção dos programas de correção de fluxo, que consistem em medidas políticas e estratégicas visando à aceleração da aprendizagem. Tanto a Bahia como Minas Gerais já empreenderam esforços nesse sentido, no entanto, as trocas de governos estaduais e municipais se configuraram como verdadeiros testes de resistência, no tocante a manutenção desses programas de correção de fluxo escolar. Atualmente, a Bahia aposta na alfabetização e Minas Gerais em políticas de reforço escolar.

A Figura 3, a seguir, apresenta as taxas de rendimento para o $\mathrm{EF}$ (I e II)7 e o EM relativas aos estados da Bahia e Minas Gerais, considerando os anos de 2011 e 2015.

As taxas de rendimento formam o grupo de indicadores que avaliam o aluno quanto ao preenchimento ou não dos requisitos de aproveitamento e frequência ao final de um ano letivo, sendo, portanto, altamente correlacionadas com as taxa de transição, especialmente promoção e repetência.

Observa-se que houve aumento das taxas de aprovação, para ambos os Estados e, consequentemente, a redução das

\footnotetext{
7 Segmentos de escolaridade, correspondendo ao primeiro ciclo do Ensino Fundamental $\left(1^{\circ}\right.$ ao $5^{\circ}$ ano) e ao segundo ciclo ( $6^{\circ}$ ao $9^{\circ}$ ano).

8 A Lei de Diretrizes e Bases da Educação instituiu um "sistema nacional de avaliação do rendimento escolar". Em seu capítulo referente à
}

demais taxas (reprovação e abandono). A análise das taxas de rendimento comprova que, se as taxas de aprovação na Bahia e em Minas Gerais estão aumentando, logo as de reprovação diminuindo, há proporcionalmente menos alunos repetentes e relativa estabilização do fluxo escolar. Entretanto, os ritmos e patamares dessa diminuição da repetência são diferentes, o que sugere persistência das desigualdades regionais em médio prazo. Assim, infere-se a existência de correlação entre a taxa de fecundidade, aprovação e matrículas iniciais e isso explica o porquê das matriculas estarem diminuindo nessas UF's.

Dados provenientes do INEP evidenciam a distorção idade-série, sobremaneira no Ensino Fundamental, como um dos maiores e incômodos entraves para a manutenção de uma educação de qualidade no Brasil. Este panorama adverso, associado as possibilidades abertas pela $\mathrm{LDB}^{8}$, favoreceu o surgimento, em todas as regiões do Brasil, da tendência em se trabalhar objetivando a otimização do fluxo escolar.

Eventos como a implantação dos ciclos referentes ao EF I e EF II, em alguns Estados, bem como a expansão das

Educação Básica, artigo 24, inciso V, alínea "b", descreve: "possibilita a aceleração de estudos para os alunos com atraso escolar". 
Figura 3. Taxas de rendimento escolar no EF (I e II) e EM, para Bahia e Minas Gerais

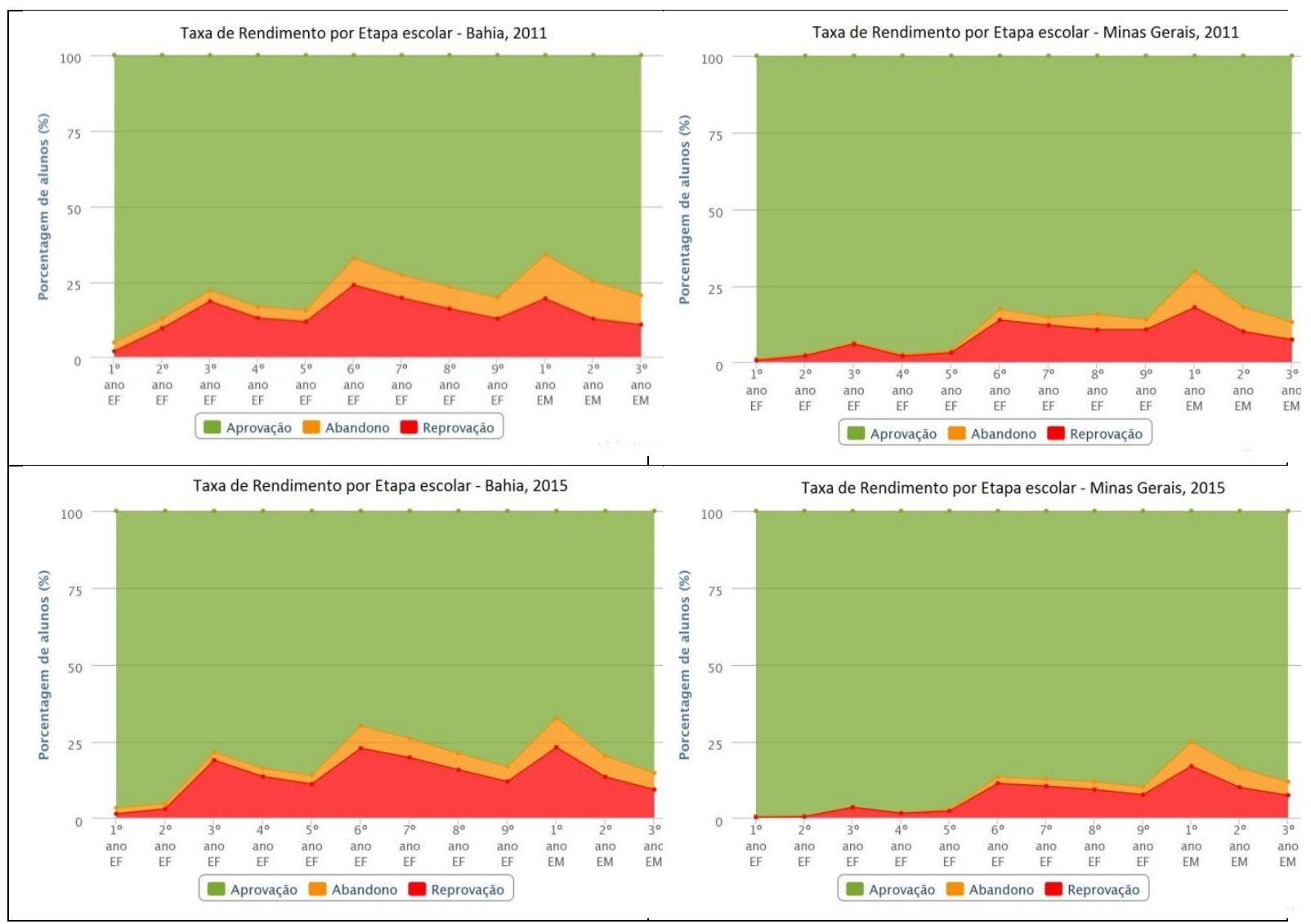

Fonte: INEP, 2011 e 2015.

classes de aceleração de aprendizagem, ou a utilização das duas estratégias juntas são exemplos típicos desta tendência. As Figuras 4, 5 e 6 evidenciam o panorama desse indicador, para o EF I e II, bem como para o EM nos municípios baianos e mineiros nos anos de 2011 e 2015, de acordo com o INEP.

A espacialização da taxa de distorção idade-série para os EF (I e II) e EM, mostra que, no período de estudo, uma tímida evolução se esboçou no que tange ao percentual de alunos frequentando o sistema de ensino baiano e mineiro com idade correta. $\mathrm{O}$ conjunto de mapas mostra certa homogeneidade das taxas na Bahia, em confronto com as verificadas em Minas Gerais, mais heterogêneas, no tocante aos ingressos no sistema educacional. 
Figura 4. Taxa de distorção idade-série para o EF I, nos municípios baianos e mineiros, 2011 e 2015

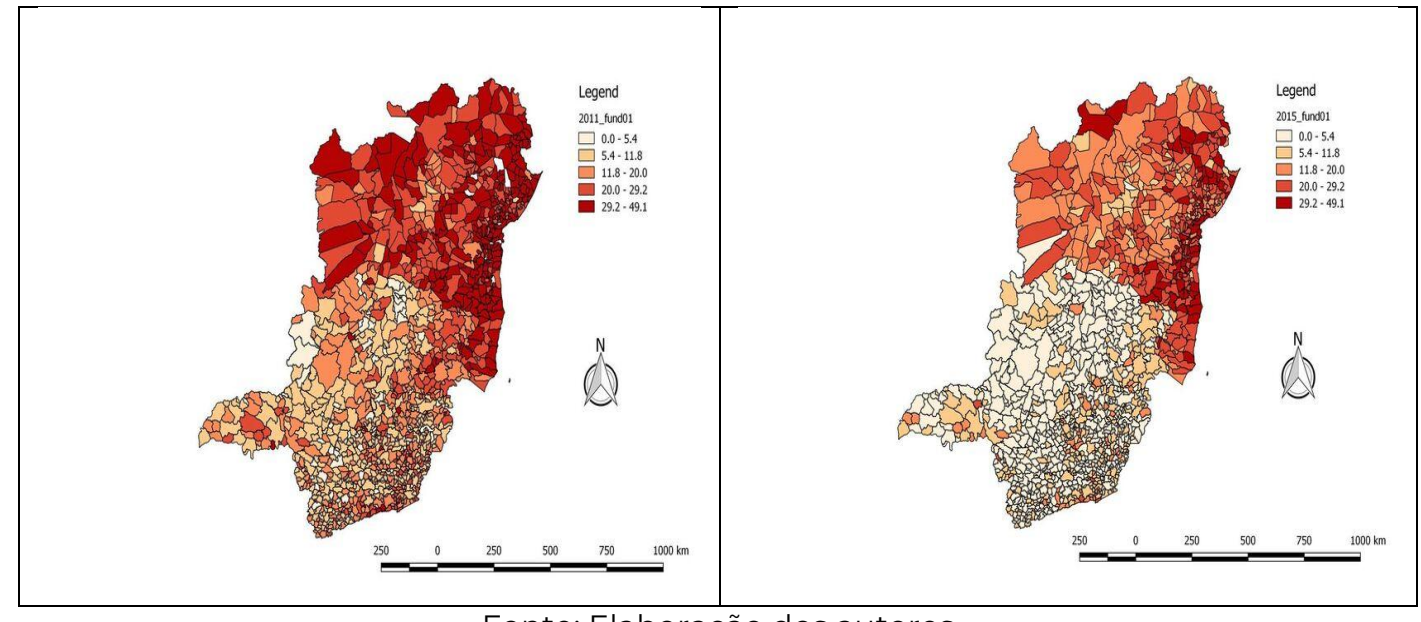

Fonte: Elaboração dos autores

Figura 5. Taxa de distorção idade-série para o EF II, nos municípios baianos e mineiros, 2011 e 2015

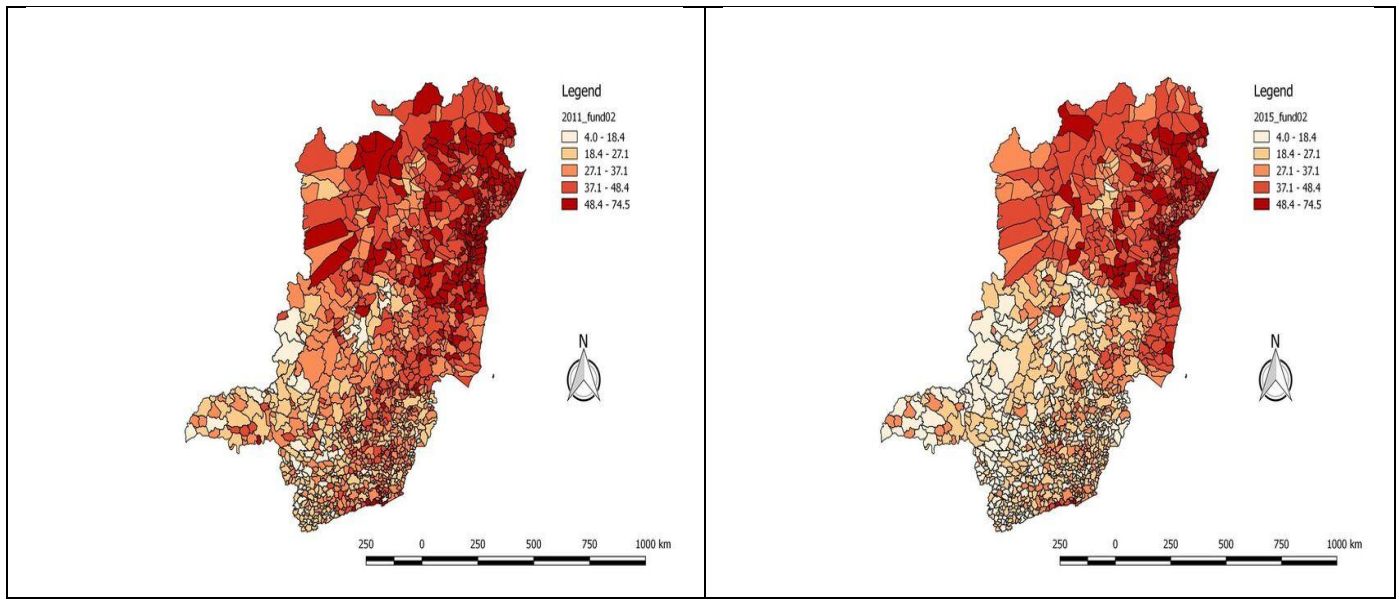

Fonte: Elaboração dos autores

Figura 6. Taxa de distorção idade-série para o EM, nos municípios baianos e mineiros,2011 e 2015

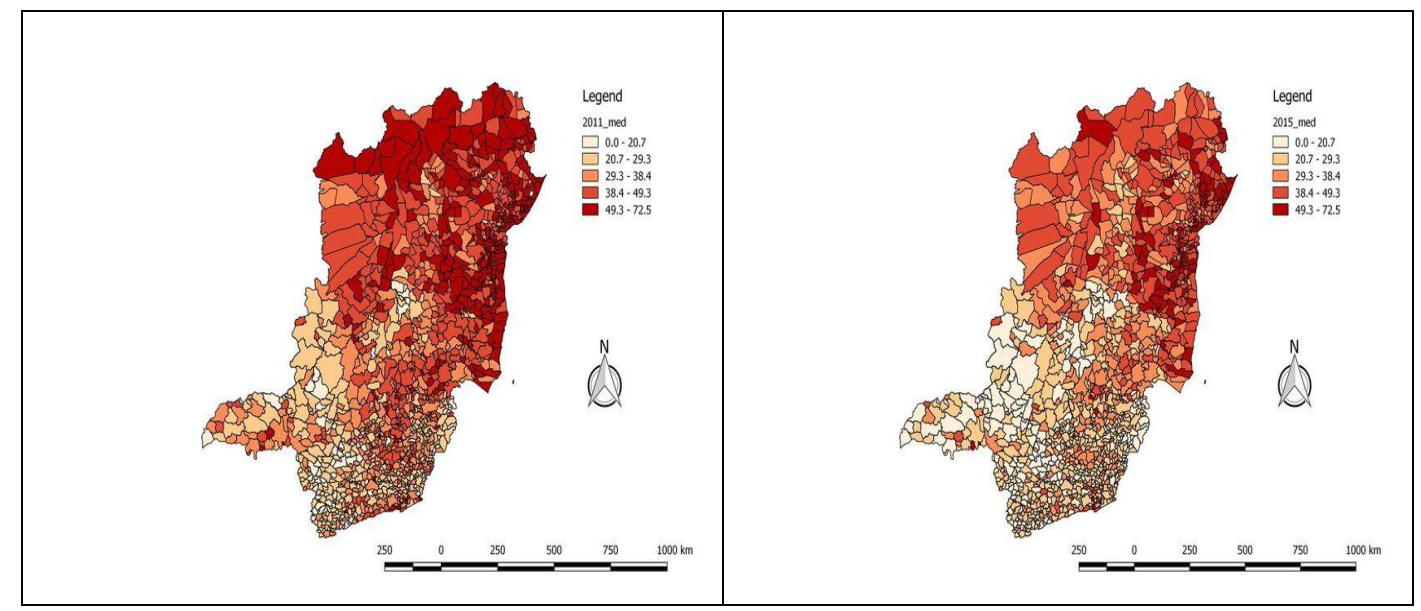

Fonte: Elaboração dos autores 


\section{CONSIDERAÇÕES FI- NAIS}

Esse estudo exploratório evidenciou que o desempenho nas escolas baianas e mineiras melhorou entre 2011 e 2015, mas, o crescimento ainda é tímido. Em todos os níveis, Fundamental e Médio, o Estado da Bahia registrou índices abaixo aos verificados no Estado de Minas Gerais. Isso denota, claramente, a desigualdade educacional entre essas unidades federativas.

Com relação à distorção idade-série, o padrão espacial verificado para a maioria dos municípios baianos e mineiros apresentou-se bastante singular. As regiões metropolitanas de Salvador e Belo Horizonte e região centro-sul mineira apresentaram os melhores indicadores, com exceção dos municípios com baixo contingente populacional em idade escolar defasada. À medida que se afasta das capitais e centros polarizadores ( $\mathrm{Na}$ Bahia os municípios de Feira de Santana, Barreiras, Camaçari e Porto Seguro, e Juiz de Fora, Uberlândia, Montes Claros em Minas Gerais) os indicadores vão piorando.

A implementação de políticas efetivas de auxílio aos municípios, por parte da União e das UF's, principalmente nos aspectos de organização das redes e da formação dos professores, constitui, a nosso ver, uma via para a paulatina redução das disparidades educacionais evidenciadas nessa pesquisa.

\section{REFERÊNCIAS BIBLIOGRÁFICAS}

Alfonsin, B. (2001). O Estatuto da Cidade e a Construção de Cidades Sustentáveis, Justas e Democráticas. In $2^{\circ}$ Congresso Brasileiro do Ministério Público de Meio Ambiente, Canela.

Azevedo, J. L.; aguiar, M. A (2001). Políticas de educação: concepções e programas. In: Associação Nacional de Política e Administração da Educação. Políticas e gestão da educação (1997-1997). Brasília: MEC/INEP/Comped. (Estado do Conhecimento, 5).

Barros, R. P.; Henriques, R.; Mendonça, R. (2002) Pelo fim das décadas perdidas: educação e desenvolvimento sustentado no brasil. ipea texto para discussão 857.

Barros, R. P., Mendonça, R., Santos, D., Quintaes, G. (2001). Determinantes do desempenho educacional no Brasil. in: ipea: textos para discussão 834. Rio de Janeiro: Ipea.

Barros, R. P.; Lam, D.(1993). Income inequality, inequality in education and children's attainment in 
Brazil, Texto para discussão $\mathrm{n}^{\circ}$ 294, Rio de Janeiro: Instituto de Pesquisa Econômica aplicada.

Berlinski, S.; Schady, N. (ed.). (2016). Os primeiros anos: o bem-estar infantil e o papel das políticas públicas. Washington, D.C: BID

Brasil. Diretoria Geral de Estatística (DGE). Estatística da instrucção. Rio de Janeiro: Typographia da estatística, 1916.

Cunha, J.; Perez, J. R.; Aidar, T. (2002). Proposta metodológica de elaboração de indicador educacional sintético para os municípios. Revista brasileira de estudos da população. campinas, sp, v. 18, n. 1/2, pp. 131-159.

Engerman, S.; Sokoloff, K. (2005). The evolution of suffrage institutions in the Americas, Journal of economic history journal of economic history, v. 65, n. 4 , p. 891921.

Engerman, S.; Sokoloff, K. (1997). Paths of growth among new world economies. in: How Latin America fell behind. Stanford: Stanford University Press.

Enguita, M. (1996). Os desiguais resultados das políticas igualitárias: classe, gênero e etnia na educação. Revista brasileira de educação, n.3, pp. 5-17.
Gatti, B. A. (2004). Estudos quantitativos em educação. Educação e pesquisa (USP), São paulo, v. 30, n. 01, pp. 11-30.

Hasenbalg, C.; Silva, N.V. (2000). Tendências das desigualdades educacionais no Brasil. Dados, Revista de ciências sociais, v. 43, n. 3, pp. 423-445.

Hirschman, A. O. (1980). Exit, voice and loyalty: Responses to decline in firms, organizations and states. Cambridge: Harvard University Press,.

Instituto brasileiro de geografia e estatística (IBGE). (2016). Indicadores sociais, 2010. disponível em: $<$ http://www.ibge.gov.br/estadossat/default.php>

Instituto Nacional de Estudos e Pesquisas Educacionais Anísio Teixeira (INEP). (2010). Nota técnica 02/2010: cálculo das taxas de rendimento escolar (censo escolar da educação básica 2009).

Instituto Nacional de Estudos e Pesquisas Educacionais Anísio Teixeira (INEP). (2015). Sinopse estatística da educação básica 20112015.

Kang, T. H. (2010). Poder político e atraso educacional no brasil, 1930-1964. Informações Fipe, São paulo, v. 355, pp. $16-20$. 
Mariscal, E.; Sokoloff, K. Schooling. (2000). Suffrage, and the persistence of inequality in the Americas, 1800-1945. In: Haber, S. political institutions and economic growth in Latin America: essays in policy, history, and political economy. stanford: Hoover Institution Press, pp. 159-217.

Oliveira, R. P. (2003). Uma dimensão avaliativa do fundef: A desigualdade regional. Educar em Revista, n. 22, pp 139-151.

Steiner, J. E. (2006). Conhecimento: gargalos para um Brasil no futuro. Estudos avançados, v. 20, n. 56, pp. 75-90. Disponível em: <http://www.usp.br>. acesso em: 10 nov. 2007.

Soares, J. F., Mambrini, J.; Pereira, L; Alves, M. T. (2001) Fatores explicativos de desempenho em língua portuguesa e matemática: A evidência do saeb-2001. brasília: inep, (mimeo).

Soares, S. et al (orgs.). (2005). Os mecanismos de discriminação racial nas escolas brasileiras. Rio de Janeiro: IPEA

Teixeira, A. (1976). Educação no Brasil. São paulo: companhia editora nacional.

Torres, H.G.; Ferreira, M. P.; Gomes, S. (2005). educação e segregação social: explorando as relações de vizinhança. in: Marques, E.; Torres, H.G. (orgs.). Segregação, pobreza e desigualdade. São Paulo: SENAC, pp. 123-142.

\section{PARA CITAR ESTE ARTÍCULO:}

Costa, C. y Moreira, R. (2017). As disparidades nos sistemas de ensino baiano e mineiro: uma análise exploratória através de indicadores educacionais. Collectivus, Revista de Ciencias Sociales, 4(2), 103-123.

DOI: http://dx.doi.org/10.15648/Coll.2.2017.6

Recibido: 21/03/2017 Aprobado: 28/05/2017 